\title{
Association Between Periodontal Health Knowledge and Oral Hygiene in Brazilian Adolescents
}

\author{
Gisele Marchetti ${ }^{\circledR}$, Fabian Calixto Fraiz ${ }^{1}$, Giselle Emilãine da Silva Reis ${ }^{1}$, Joana Leticia \\ Vendruscolo $^{1}$ (1), Luciana Reichert da Silva Assunção ${ }^{1(0)}$
}

${ }^{1}$ Department of Stomatology, Universidade Federal do Paraná, Curitiba, PR, Brazil.

Author to whom correspondence should be addressed: Prof Dr Luciana Reichert da Silva Assunção, Department of Stomatology, Pediatric Dentistry, Universidade Federal do Paraná, Avenida Prefeito Lothário Meissner, 632, Jardim Botânico, Curitiba, Paraná, Brazil. 80210-170. Phone: +55 4133604025. E-mail: lurassuncao@yahoo.com.br.

Academic Editors: Alessandro Leite Cavalcanti and Wilton Wilney Nascimento Padilha

Received: 15 August 2019 / Accepted: 24 March 2020 / Published: 20 April 2020

How to cite this article: Marchetti G, Fraiz FC, Reis GES, Vendruscolo JL, Assunção LRS. Association between periodontal health knowledge and oral hygiene in Brazilian adolescents. Pesqui Bras Odontopediatria Clín Integr. 2020; 20:e5 133. https://doi.org/10.1590/pboci.2020.071

\begin{abstract}
Objective: To evaluate the influence of oral health knowledge in adolescents' oral hygiene pattern. Material and Methods: Cross-sectional study involving 291 participants aged between 14 and 19 years old enrolled in a public school in Curitiba, Brazil. A self-administered questionnaire containing five affirmations about periodontal diseases and their forms of prevention was arranged on a three-point Likert scale. Correct answers were given a weight $=1$ and incorrect ones, weight $=0$. The knowledge score $(\mathrm{KS})$ was determined by the sum. Socioeconomic and demographic data were obtained by a questionnaire sent to those responsible. The oral hygiene pattern was evaluated through the simplified oral hygiene index (OHI-S) by a calibrated researcher $(K=0.89)$. Mann-Whitney $\mathrm{U}$ test and univariate and multivariate Poisson regression with robust variance were used for data analysis $(\alpha=0.05)$. Results: There was an inversely proportional association between KS and OHI-S ( $\mathrm{p}=0.018)$. The multiple model showed that adolescents with a lower KS (PR = 0.93, CI95\%: 0.88-0.99), male gender ( $\mathrm{PR}=1.17$, CI95\%: 1.01-1.37) and whose caregivers presented a lower level of education ( $\mathrm{PR}=1.30$, CI95\%: 1.03-1.64) showed a higher index of dental plaque. Conclusion: The level of oral health knowledge, the gender and the caregivers' level of education influences the adolescents' oral hygiene pattern.
\end{abstract}

Keywords: Health Knowledge, Attitudes, Practice; Oral Health; Dental Plaque; Adolescent. 


\section{Introduction}

Acquiring healthy habits that may result in good oral health is an important aspect of adolescence. At this stage of life, individuals undergo significant physical, hormonal, psychological, and behavioral changes [1]. This is the ideal time to offer oral health interventions, to break patterns of behavior and to change them positively [2].

In spite of this, it is also in adolescence that oral health care is more neglected [3]. In this sense, the last survey of the periodontal profile conducted by the World Health Organization showed that the number of adolescents with gingivitis increased substantially in many countries, with a higher incidence in the less developed countries [4]. Gingivitis when untreated, can progress to periodontitis, mobility and tooth loss [5], and the initial stages of the disease are associated with poor oral hygiene, regardless of socioeconomic status [6].

In Brazil, a population-based study involving all regions of the country verified the existence of a directly proportional relationship between worse periodontal health conditions and age. Thus, among adolescents with 12-year-olds, $37 \%$ had gingivitis, which increased to $49.1 \%$ among 15 -19-year-old and $82.2 \%$ in adults' aged 35-44 years [7]. These data demonstrate the importance of establishing oral health promotion measures in the early stages of life, since childhood and adolescence are decisive periods in the construction of new behaviors [8].

Health knowledge has a direct influence on the behaviors and habits that individuals adopt in their hygiene and personal care [9]. This fact also applies to dentistry, with a directly proportional relationship between higher levels of knowledge with better oral health conditions [10]. Therefore, promoting actions that increase knowledge of oral health is an important factor to be invested in the adoption of healthy habits that promote the oral health of adolescents.

A study conducted in India involving 279 individuals aged 8 to 11 years evaluated the efficacy of different methods of health education and observed a relationship between greater knowledge in oral health with better oral hygiene conditions [11]. These results demonstrate that an increased knowledge of oral health in adolescence may prevent the development of several comorbidities, and oral health education is a simple, low-cost and well-accepted method at this stage of life [12].

Considering the high prevalence of periodontal diseases in Brazilian adolescents [7] and its direct relation with the levels of knowledge in oral health, the development of researches that explore this aspect is justified. The objective of this study was to evaluate the association of oral health knowledge and the plaque index in adolescents, besides the influence of socioeconomic, demographic and behavioral factors in this index. It is expected that, with the results of this investigation, it will be possible to institute effective educational actions and behavior modification, especially in the groups of greater risk to the development of periodontal diseases.

\section{Material and Methods}

Study Design and Sample Selection

Cross-sectional study involving adolescents of both genders, aged 14 to 19 years, enrolled in technical secondary education at a public school in the city of Curitiba, Paraná, Brazil. Exclusion criteria were participants with some physical or mental condition that made the interventions impossible, adolescents using fixed orthodontic devices at the moment of clinical examination, incomplete questionnaires, and adolescents 
from technical courses related to the area of oral health. The duration of the survey was from July to August 2016.

For the sample calculation, the comparison of means was used considering the unequal variances. For this calculation, the outcome was considered the "knowledge score" (KS). In a pilot study, the mean and standard deviation of KS among adolescents with low platelet index (OHI-S $\leq 1)$ were 2.50 and 0.70 , respectively, and among participants with a high index of (OHI-S $>1)$ mean of 2.86 and standard deviation of 1.46. Considering a $5 \%$ error and $80 \%$ test power, a total sample value of 250 was found. Estimating a loss of $20 \%$, the final sample totaled 300 individuals.

\section{Pilot Study}

A pilot study was carried out to test the feasibility and methodological applicability of the instruments. In addition, this phase served to verify the dynamics of the application of the instruments and the average time spent with each participant. For its accomplishment, 15 adolescents between ages 14 and 19 were selected, who were not included in the main study. The methodological design was adequate, however, some of the terms of the questionnaire were modified to allow a greater understanding on the part of the participants.

\section{Data Collection}

A previously tested questionnaire was used to evaluate the participants' level of knowledge about periodontal diseases, previous dental history, self-perception of the mouth [7] and the use of tobacco [13]. During the application of the questionnaire, the students were supervised by the researchers to ensure that no interpersonal communication occurred.

In order to evaluate adolescents' knowledge of periodontal diseases and their prevention methods, five statements were used: 1: If I have good oral hygiene I have less possibility of having gingival bleeding; 2 : Whoever brushes their teeth very well does not need to floss; 3: It is not possible to remove the calculus and tartar with dental brushing; 4: Cleaning with mouthwashes may exclude flossing; and 5: A person may lose their teeth because they have problems with their gums and periodontium. In order to obtain the knowledge score (KS), the answers were arranged in a three-point Likert scale, being: I agree, do not agree and neither disagree nor disagree. Correct answers were scored 1 (one), and incorrect and "do not know" score o (zero). Scores ranged from five (higher knowledge) to zero (less knowledge).

Those responsible for the adolescents also answered a questionnaire containing socioeconomic and demographic information, and the evaluation followed the criteria of the Brazilian Association of Research Companies. This classification stratifies families into social classes (A, B1, B2, C1, C2, D-E) by using a scoring system assigned according to the educational level of the head of the household, possession of household items from a previously prepared list (number of bathrooms, cars, microcomputers, dishwashers, refrigerators, freezers, washing machines, DVDs, microwaves, motorcycles, clothes dryers and the presence of a maid) and family access to public services. The score obtained with these criteria may vary from 0 to 100 . The individuals are categorized into 8 economic classes, ranging from A1 (highest economic class) to E (lowest economic class). Class A is applied, when the scores vary from 45 to 100 points, Class B1, from 38 to 44 points, Class B2, from 29 to 37 points, Class C1, from 23 to 28 , Class C2 from 17 to 22 points and Class D-E from o to 16 points. Class A refers to those with higher purchasing power and class D-E to those with lower income [14]. 
Clinical evaluations were performed shortly after the questionnaire was applied. The oral hygiene standard was obtained through the simplified oral hygiene index (OHI-S) [15]. An examiner (GM) was previously calibrated, comparing his results to those of a researcher with extensive experience in epidemiological studies (FCF) to determine the inter-examiner agreement. The Kappa test was used, obtaining a value of 0.89 , being considered an excellent agreement [16]. It was not possible to obtain the intra-examiner agreement index, since this index depends on the visualization of the amount of plaque at the moment of the examination, therefore, the oral hygiene condition could change for the same individual if the evaluation was performed at different times, compromising the agreement of the diagnosis. The collection of this index was performed in a classroom, in which the students remained seated in chairs, and the evaluations were carried out individually, with artificial light, use of gauze and a millimeter probe.

\section{Statistical Analysis}

Data was evaluated through descriptive analysis, followed by bivariate analysis (Mann-Whitney U test). Univariate and multivariate Poisson Regression analyzes with robust variance were performed, estimating the prevalence ratio and its respective 95\% confidence interval (CI) The dependent variable was the presence of dental plaque, dichotomized in: OHI-S $>1$ (high dental plaque index) and OHI-S $\leq 1$ (low dental plaque index). The independent variables were categorized according to theoretical or median criteria: knowledge score as quantitative variable, gender (Male/Female), age (" $\leq 16$ years"/" $\geq 17$ years"), economic classification ("in or above class B" / "in or below class C"), previous history of gum disease ("Yes"/"No"), age of contact with the first cigarette (" never smoked "or" $\geq 17$ years "/" $\leq 16$ years "), schooling of the household head ("8 years of schooling "/" $\leq 8$ years of schooling"). A stepwise forward selection model was used. All independent variables that presented a $\mathrm{P}$ value $<0.20$ in the univariate analysis were selected. The remaining values were maintained in the final model $(\mathrm{p}<0.05)$ after adjustment. The fit of the final model was also validated using Pearson's chi-square goodness-of-fit test. Statistical analysis was performed using the STATA program, version 12.0 (StataCorp LP, College Station, USA). The level of significance was 5\%. Two-tailed test was used in all analyzes.

Ethical Aspects

The investigation followed the parameters of the Declaration of Helsinki and was approved by the Human Ethics Committee of the Federal University of Paraná (Protocol No. 51712315.4.0000.0102).

\section{Results}

A total of 291 adolescents participated in this study (response rate $=97.0 \%$ ), of which $159(54.6 \%)$ were female. The mean age among participants was 16.1 years $( \pm 1.21)$. Only 10 questionnaires sent to those responsible were not answered (3.4\%), and the majority were filled by mothers (69.3\%), followed by fathers $(26.8 \%)$. The average monthly family income of the sample was $\mathrm{R} \$ 4174.75$ ( \pm 2390.82$)$ which corresponds to U\$ 1284.53 in the moment of the study. The majority of the adolescents' responsible had more than 8 years of schooling (96.2\%) and belonged to equal to or greater than class B (77.8\%) (Table 1).

Regarding the number of correct answers in the five statements, it was found that $226(77.7 \%)$ correctly answered the statement 1, 230 (79.3\%) affirmed 2, only 62 (21.3\%) statement 3, and, finally, statements 4 and 5 presented $74.9 \%$ and $59.8 \%$ of correct answers, respectively. The mean knowledge score was 3.13 ( \pm 1.15$)$, median of 3.00 and amplitude of 0 to 5 . 
Table 1. Characteristics of the study population.

\begin{tabular}{lc}
\multicolumn{1}{c}{ Variables } & $\mathbf{N}(\%)$ \\
\hline $\begin{array}{l}\text { Age (Mean and SD) } \\
\text { Sex }\end{array}$ & $16.1( \pm 1.21)$ \\
Female & $159(54.6)$ \\
Male & $132(45.4)$ \\
Monthly Family Income (Average and SD)* & $\mathrm{R} \$ 4174.75( \pm 2390.82)$ \\
Years of Schooling of the Household Head & $280(96.2)$ \\
$\geq 8$ Years Old & $11(3.8)$ \\
$<8$ Years Old & $39(14.0)$ \\
Socioeconomic Classification & $178(63.8)$ \\
A & $64(21.5)$ \\
B & $2(0.7)$ \\
C & $3.13( \pm 1.15)$ \\
D and E & \\
Knowledge Score (Mean and SD) & \\
*Amounts in Reais; Frequencies smaller than 291 are due to the absence of data for the variable.
\end{tabular}

There was consent of all the adolescents for the clinical examination. The dental biofilm examination showed an OHI-S mean of 1.26 ( \pm 0.37) with a minimum of 0 and a maximum of 2.17 . A total of $205(70.4 \%)$ participants presented OHI-S >1. It was observed that the adolescents with greater knowledge on the issue of dental floss presented lower plaque indexes $(\mathrm{p}=0.013)$.

There was an inverse and statistically significant association between the knowledge score and OHI-S $(\mathrm{p}=0.018)$, with a mean score of $3.41( \pm 0.98)$ and a median of 3.5 among adolescents with lower plaque indexes $(\mathrm{OHI}-\mathrm{S} \leq 1)$. For participants with OHI-S $>1$, the mean of the knowledge score was $3.03( \pm 1.19)$ and the median was 3.0. The multiple model showed that adolescents with a lower knowledge score, male and whose parents had low educational level, had a higher plaque index. The final model showed a good fit $(\mathrm{p}=1.0000)$ (Table 2 ).

Table 2. Univariate and multivariate Poisson regression model.

\begin{tabular}{|c|c|c|c|c|}
\hline Variables & $\begin{array}{c}\text { Unadjusted RP } \\
(95 \% \mathrm{IC})\end{array}$ & p-value & $\begin{array}{c}\text { Adjusted RP } \\
(95 \% \mathrm{IC})\end{array}$ & p-value \\
\hline Knowledge Score & $0.92(0.86-0.97)$ & 0.004 & $0.93(0.88-0.99)$ & 0.019 \\
\hline \multicolumn{5}{|l|}{ Sex } \\
\hline Female & 1 & & & \\
\hline Male & $1.01(1.05-1.41)$ & 0.009 & $1.17(1.01-1.37)$ & 0.037 \\
\hline \multicolumn{5}{|l|}{ Age } \\
\hline$\geq 17$ Years & 1 & & & \\
\hline$\leq 16$ Years & $0.95(0.82-1.11)$ & 0.534 & - & - \\
\hline \multicolumn{5}{|l|}{ Socioeconomic Classification } \\
\hline Equal to or Greater Than Class B & 1 & & & \\
\hline Equal to or Less Than Class C & $1.03(0.85-1.23)$ & 0.778 & - & - \\
\hline \multicolumn{5}{|l|}{ Previous History of Gum Disease } \\
\hline No & 1 & & & \\
\hline Yes & $1.06(0.89-1.26)$ & 0.541 & - & - \\
\hline \multicolumn{5}{|l|}{ First Contact with Tobacco } \\
\hline Never, $\geq 17$ Years Old & 1 & & & \\
\hline$\leq 16$ Years Old & $1.09(0.85-1.40)$ & 0.505 & - & - \\
\hline \multicolumn{5}{|l|}{ Years of Schooling of the Household Head } \\
\hline$\geq 8$ Years Old & 1 & & & \\
\hline$<8$ Years Old & $1.30(1.06-1.60)$ & 0.010 & $1.30(1.03-1.64)$ & 0.028 \\
\hline
\end{tabular}

$\overline{\mathrm{PR}}=$ Prevalence Ratio; CI = Confidence Interval; Frequency lower than 291 are due to the absence of data for the variable; Pearson's chisquare goodness-of-fit test $=84.88158 ;$ p-value $=1.0000$. 


\section{Discussion}

This cross-sectional study evaluated the relationship between knowledge and plaque index in adolescents. The results is showed an independent association between the knowledge score and the plaque index with a lower mean knowledge score in adolescents with a higher plaque index than those with the lowest indexes. This fact can be explained by the positive influence of knowledge on habits and care with oral health [5]. In a study of 810 Indian adolescents aged 15 to 18 years with similar socioeconomic characteristics of this study, they observed a positive linear correlation between greater knowledge and better attitudes and practices related to oral health [17].

A randomized controlled trial of 10 to 11-year-old Pakistani adolescents evaluated different teaching methods and their influence on behavior, knowledge and oral hygiene index. The authors observed that the increase in knowledge was related to an improvement in the oral hygiene index [8]. These findings corroborate another study carried out with 279 Indian children aged 8 to 11 years who evaluated the effect of teaching methods on knowledge and the OHI-S index. It was observed that greater knowledge was associated with a decrease in the scores of the index [11].

Among the statements used in this study, there was a low percentage of correct answers to the question "it is not possible to remove the calculus/tartar with toothbrushing". These results demonstrate that the role that the dental professional plays in oral health is not yet clear in this specific age group. The last oral health survey done by the Brazilian Ministry of Health (SB Brasil - 2010) reported that only 16.2\% of Brazilian adolescents nationwide and $18.8 \%$ in the Southwestern Region had visited a dentist within the past three years. In this study, the presence of dental calculus was a marked periodontal alteration among the Brazilian adolescents [7]. It can be verified that the low knowledge in aspects related to the etiological factors of the periodontal disease and its forms of treatment is still an important factor and deserves to be inserted in educational actions of health promotion for this specific age group.

In this survey most adolescents correctly answered more than half of the statements. A previous study conducted with young Indians also showed a high knowledge (90.9\%) in oral health [17]. This result suggests that, at present, adolescents have easy access to the media where aspects related to oral health can also be transmitted [18]. However, it is necessary that the acquisition of knowledge is transformed into actions so that the habits are incorporated into the daily life of the individual [19].

The specialized literature states that flossing is an adequate and recommended tool for removal of the dental biofilm from proximal surfaces [20,21]. In this study it was observed that adolescents with greater knowledge about the use of dental floss presented lower plaque indexes, suggesting that, in these individuals, oral hygiene is performed in a more adequate way. However, it is common that, over time, adolescent motivation to floss diminishes, once supervision ceases, suggesting that oral health promotion and prevention actions should be constantly reinforced as there is a strong component at this stage of life [18].

In this study, most of the participants $(70.4 \%)$ had a high index of dental biofilm. In agreement with this result, a study carried out with Iranian adolescents showed that all the evaluated youngsters had a high index of dental biofilm and 93\% of them had gingival bleeding [23]. These results confirm the fact that adolescence is a risk phase for oral diseases [18], reinforcing the need for intervention studies in this age group.

In the multiple model, adolescents with lower knowledge, males and those whose parents had a low educational level showed higher rates of dental plaque. These results corroborate previous studies that demonstrate that the low level of schooling of the responsible ones is a negative factor that influences in the 
worse conditions and habits of oral health in the children [17,24]. Also, a previous study indicated that adolescents of the female gender present greater knowledge, better practices and behavior in oral health than those of the masculine gender [17], mainly due to the greater concern they have with body and facial image, besides a less anxiety or fear of visits to the dentist [24,17].

This study aimed at individuals with high risk for oral diseases, especially those that compromise gingival and periodontal health, and therefore deserving of public health actions in order to avoid the perpetuation of these diseases to adulthood. In this sense, this study suggests that increasing oral health knowledge may decrease the dental biofilm index, which is a determinant factor for the development of periodontal diseases [22]. The positive points of this work were that all the instruments used were previously tested, in addition to the calibration to evaluate the OHI-S index. However, it presents limitations inherent to cross-sectional studies, besides being performed in only one place, compromising the external validity and generalization capacity for other populations.

\section{Conclusion}

The knowledge about oral health influences the oral hygiene pattern of adolescents. Male participants and those with low educational levels may present a greater risk of poor oral hygiene. These findings reinforce the importance of establishing effective and behavioral educational actions in adolescence, including those that aim to generate in these individuals' practices that may reflect better oral health conditions.

\section{Authors' Contributions}

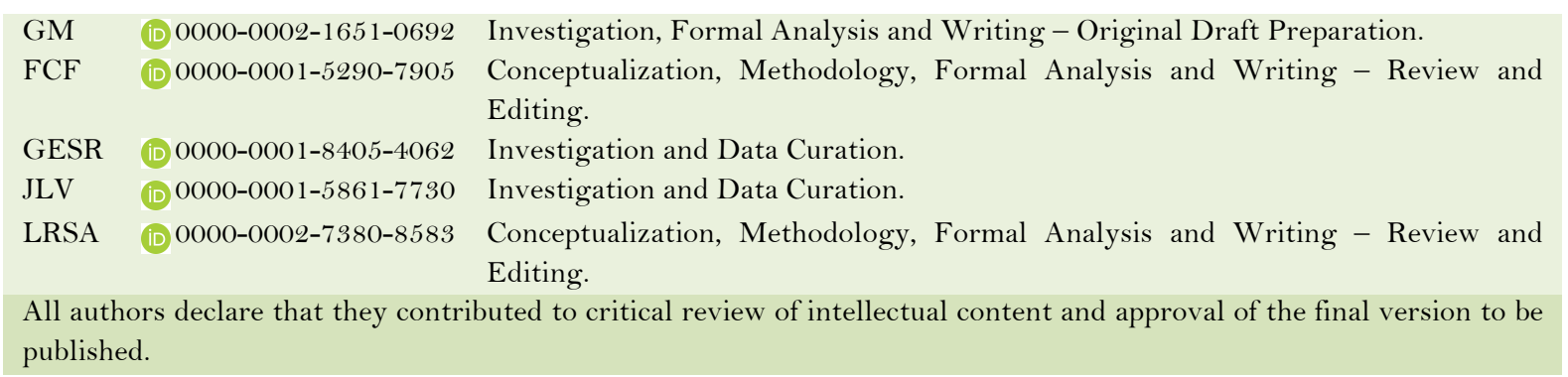

\section{Financial Support}

This study was financed in part by the Coordenação de Aperfeiçoamento de Pessoal de Nível Superior - Brasil (CAPES) Finance Code 001.

\section{Conflict of Interest}

The authors declare no conflicts of interest.

\section{References}

[1] Al-Jewair TS, Suri S, Thompson BD. Predictors of adolescent compliance with oral hygiene instructions during twoarch multibracket fixed orthodontic treatment. Angle Orthod 2011; 81(3):525-31. https://doi.org/10.2319/092010-547.1

[2] Wu L, Gao X, Lo ECM, Ho SMY, McGrath C, Wong MCM. Motivational interviewing to promote oral health in adolescents. J Adolesc Health 2017; 61(3):378-84. https://doi.org/10.1016/j.jadohealth.2017.03.010

[3] Muniz FWMG, da Silva LH, Rösing CK, Martins RS, Moreira MMSM, Carvalho RS. Efficacy of an unwaxed dental floss impregnated with $2 \%$ chlorhexidine on control of supragingival biofilm: a randomized, clinical trial. J Investig Clin Dent 2018; 9(1):52-61. https://doi.org/10.1111/jicd.12280 
[4] World Health Organization. Periodontal Country Profiles, 2016. Available from: http://www.dent.niigatau.ac.jp/prevent/perio/perio.html. [Accessed on February 26, 2017].

[5] Shizuma Y, Zaitsu T, Ueno M, Ohnuki M, Kawaguchi Y. Relationship between self-assessment and clinical evaluation of dental plaque and gingival condition in Japanese adolescents. Int J Dent Hyg 2018; 16(1):144-50. https://doi.org/10.1111/idh.12281

[6] Chambrone L, Macedo SB, Ramalho FC, Trevizani Filho E, Chambrone LA. Prevalência e severidade de gengivite em escolares de 7 a 14 anos: condições locais associadas ao sangramento à sondagem. Cien Saúde Coletiva 2010; 15(2):337-43. https://doi.org/10.1590/S1413-81232010000200008

[7] Projeto SB Brasil 2010. Pesquisa Nacional de Saúde Bucal. Available from: http://bvsms.saude.gov.br/bvs/publicacoes/pesquisa_nacional_saude_bucal.pdf. [Accessed on February 26, 2017]. [In Portuguese]

[8] Haleem A, Siddiqui MI, Khan AA. School-based strategies for oral health education of adolescents - a cluster randomized controlled trial. BMC Oral Health 2012; 18(12):54-66. https://doi.org/10.1186/1472-6831-12-54

[9] Jordão LMR, Malta DC, Freire MDCM. Simultaneous oral health risk behaviors among adolescents: evidence from the National School-based Student Health Survey. Rev Bras Epidemiol 2018; 29(21):e180019. https://doi.org/10.1590/1980-549720180019.supl.1

[10] Marchetti G, Fraiz FC, Nascimento WMD, Soares GMS, Assunção LRDS. Improving adolescents' periodontal health: evaluation of a mobile oral health app associated with conventional educational methods: a cluster randomized trial. Int J Pediatric Dent 2018; 28(4):410-9. https://doi.org/10.1111/ipd.12371

[11] Jain S, Bhat N, Asawa K, Tak M, Singh A, Shinde K, et al. Effect of training school teachers on oral hygiene status of 8-10 years old government school children of Udaipur city, India. J Clin Diagn Res 2016; 10(8):95-9. https://doi.org/10.7860/JCDR/2016/18576.8330

[12] Gonçalves LFF, Faria DSA, Batista ES, Ferreira SR, Assis SM. Health promotion with teenagers in the school environment: experience report. Sanare 2016; 15(2):160-7.

[13] World Health Organization. Global school-based student health survey 2013. Available from: http://www.who.int/chp/gshs/GSHS_Core_Modules_2013_Spanish.pdf. [Accessed on February 26, 2017].

[14] Associação Brasileira de Empresas de Pesquisa. Critérios de Classificação Econômica Brasil, Brazilian Association of Research Companies. Brazil Economic Classification Criteria 2015. Available fom: http://www.abep.org/criteriobrasil. [Accessed on August 27, 2016].

[15] Greene JC, Vermillion JR. The simplified oral hygiene index. J Am Dent Assoc 1964; 68(1):7-13. https://doi.org/10.14219/jada.archive.1964.0034

[16] Landis JR, Koch GG. The measurement of observer agreement for categorical data. Biometrics 1977; 33(1):159-74. https://doi.org/10.2307/2529310

[17] Wahengbam PP, Kshetrimayum N, Wahengbam BS, Nandkeoliar T, Lyngdoh D. Assessment of oral health knowledge, attitude and self-care practice among adolescents - a state wise cross-sectional study in Manipur, North Eastern India. J Clin Diagn Res 2016; 10(3):65-70. https://doi.org/10.7860/JCDR/2016/20693.8002

[18] Mattos-Silveira J, Matos-Lima BB, Oliveira TA, Jarroug K, Rego RV, Reyes A, et al. Why do children and adolescents neglect dental flossing?. Eur Arch Pediatric Dent 2017; 18(1):45-50. https://doi.org/10.1007/s40368-016-0266-4

[19] Al Subait AA, Alousaimi M, Geeverghese A, Ali A, Metwally AE. Oral health knowledge, attitude and behavior among students of age 10-18 years old attending Jenadriyah festival Riyadh: a cross-sectional study. Saudi J Dent Res 2016; 7(1):45-50. https://doi.org/10.1016/j.sjdr.2015.05.001

[20] American Dental Association. Federal Government, ADA emphasizes importance of flossing and interdental cleaners, 2016. Available from: http://www.ada.org/en/pressroom/news-releases/2016. [Accessed on March 20, 2020].

[21] Australian Dental Association. Flossing, 2017. Available from: https://www.ada.org.au/Dental-Health-Week2017/Oral-Health-for-Busy-Lives/Flossing. [Accessed on March 20, 2020].

[22] Levin L, Margvelashvili V, Bilder L, Kalandadze M, Tsintsadze N, Machtei EE. Periodontal status among adolescents in Georgia. A pathfinder study. Peer J 2013; 17(1):e137. https://doi.org/10.7717/peerj.137

[23] Jain M, Namdev R, Bodh M, Dutta S, Singhal P, Kumar A. Social and behavioral determinants for early childhood caries among preschool children in India. J Dent Res Dent Clin Dent Prospects 2015; 9(2):115-20. https://doi.org/10.15171/joddd.2014.023

[24] Kateeb E. Gender-specific oral health attitudes and behavior among dental students in Palestine. East Mediterr Health J 2010; 16(3):329-33. 